\title{
Long-term monitoring of a mercury contaminated estuary (Ria de Aveiro, Portugal): the effect of weather events and management in mercury transport
}

\author{
J. P. Coelho, ${ }^{1 *}$ P. Pato, ${ }^{1,2}$ B. Henriques, ${ }^{1}$ A. Picado,${ }^{3}$ A. I. Lilleb $\varnothing,{ }^{4}$ J. M. Dias, ${ }^{3}$ A. C. Duarte,${ }^{1}$ \\ M. E. Pereira ${ }^{1}$ and M. A. Pardal ${ }^{5}$ \\ ${ }^{1}$ Department of Chemistry \& CESAM, University of Aveiro, 3810-193 Aveiro, Portugal \\ ${ }^{2}$ School of Technology and Management, Polytechnic Institute of Viana do Castelo, Avenida do Atlântico, 4900-348 Viana do Castelo, Portugal \\ ${ }^{3}$ Department of Physics and CESAM, University of Aveiro, 3810-193 Aveiro, Portugal \\ ${ }^{4}$ Department of Biology \& CESAM, University of Aveiro, 3810-193 Aveiro, Portugal \\ ${ }^{5}$ CFE - Centre for Functional Ecology, Department of Life Sciences, University of Coimbra, Apartado 3046, 3001-401 Coimbra, Portugal
}

\begin{abstract}
:
The main aim of this research was to assess the mercury transport from an estuarine basin with a background of anthropogenic contamination during a spring tidal cycle (year 2009) and compare it with two previous tidal cycles (years 1994 and 1999), as part of a long-term monitoring program.

Results showed that effective mercury transport occurs both in the dissolved and particulate fractions $(0.18$ and $0.20 \mathrm{~kg}$ per tidal cycle, respectively), and despite an overall decrease in environmental contamination, results more than double previous findings on particulate transport in the system. These findings result essentially from changes in the tidal prism (net export of $2 \mathrm{million}^{3}$ of water), given that both dissolved and particulate concentrations did not increase over time. Hydrodynamic simulations were performed to evaluate the effect of physical disturbance (dredging) and weather events (increased freshwater flow) in these processes, and results suggest the increased freshwater flow into the system as the main forcing function for the mercury transport increment. These results highlight the importance of long-term monitoring programs, since despite an overall improvement in local contamination levels, the enhancement of transport processes through hydrological changes increases environmental pressure away from the contamination source. Copyright (C) 2012 John Wiley \& Sons, Ltd.
\end{abstract}

KEY WORDS mercury; gydrology; tidal cycle; fluxes; long-term monitoring; weather events

Received 13 March 2012; Accepted 1 October 2012

\section{INTRODUCTION}

Estuarine catchments are strategic settings throughout human history, either as places of navigation, agricultural abundance or as locations of the biggest cities in the World (Kennish, 1996; Mclusky and Elliot, 2004). Prime sites of land reclamation for industry and agriculture, estuaries have become repositories of industrial and domestic effluents, resulting in increased ecological stress. Multiple anthropogenic pressures such as human population growth, progressive industrialization and intensive agriculture are endangering such aquatic environments, and have instigated a growing international consciousness towards assessing the current status and protecting these ecosystems. Considering that system response times can sometimes be of the order of 20-30 years, and short-term fluctuations caused by climatic variations may be misinterpreted as trends, long-term monitoring of impacted ecosystems is an essential tool to assess environmental trends and the evolution of ecosystem status (Burt et al., 2008).

*Correspondence to: J.P. Coelho, Department of Chemistry and CESAM, University of Aveiro, 3810-193 Aveiro, Portugal

E-mail: jpcoelho@ua.pt
The resilience of metallic contaminants in the environment, as well as their affinity to sediments, has resulted in persistent contamination issues in sites with historical anthropogenic influence. In the specific case of mercury, temporal contamination trend studies have been reported for mining sites such as Almadén (Berzas Nevado et al., 2003), New Almadén (Conaway et al., 2004) or Idrija (Horvat et al., 1999), but also for systems near chlor-alkali industries (Gagnon et al., 1997; Harland et al., 2000; Ram et al., 2003; Hissler and Probst, 2006), and rely either on repeated measurements (Harland et al., 2000; Laurier et al., 2004) or sediment core analysis and dating (Conaway et al., 2004; Ip et al., 2004; Mason et al., 2004) to assess the evolution of contamination levels. After the removal of the contamination agent (closure of mines or industries), natural remediation (i.e. through eventual burial by sedimentation of particles with lower $\mathrm{Hg}$ content) usually takes place over time (Wang et al., 2004; Ridal et al., 2010), but not necessarily reducing the contaminant bioavailability to resident biota (Ridal et al., 2010), therefore justifying further monitoring and research.

The Ria de Aveiro (Western coast of Portugal) was for decades the endpoint of effluents discharged from a nearby industrial cluster. Untreated effluents were dumped in a stream (Estarreja channel) leading to the Laranjo Basin, 
including those from a chlor-alkali industry using mercury cathodes in their production method. These effluents were highly enriched in this metal and induced an environmental contamination gradient inside the lagoon (Pereira et al., 2009). Considerable attention has been given to the mercury contamination problems of the Ria de Aveiro, justified by the estimated storage in the system of $33 \times 10^{3} \mathrm{~kg}$ of this contaminant, of which $77 \%$ is in the Laranjo Basin area (Pereira et al., 2009). The main focus has been, until recently, on the dissolved, particulate and sedimentary fractions and, in a lesser extent, on estuarine biota contamination (Pereira et al., 2009). From existing studies, a pattern of decreasing mercury concentrations in surface sediments emerges, as a result of implementation of an effluent treatment plant (Pereira et al., 1997) and changes in production technology (OSPAR, 2004; Pereira et al., 2009). A similar trend was observed in the dissolved fraction of the water column (from the $\mu \mathrm{g}^{-1}$ range in the 90's (Pereira et al., 1997) to a maximum of $53 \mathrm{ng}^{-1}$ in 2001 (Ramalhosa et al., 2001)) and in the suspended particulate matter (SPM) mercury content (from up to $1500 \mathrm{mg} \mathrm{kg}^{-1}$ (Pereira et al., 1997) to a maximum of $26 \mathrm{mg} \mathrm{kg}^{-1}$ (Ramalhosa et al., 2001)).

Considering estuarine biota contamination, existent information for this system suggests that despite the significant decrease in surface sediment contamination, estuarine biota are still subject to relevant mercury bioaccumulation. Regulatory threshold for consumption infringements were recently observed for the bivalve Scrobicularia plana (Coelho et al., 2006), the crab Carcinus maenas (Coelho et al., 2008) or the fish Dicentrarchus labrax (Pereira et al., 2009), symptomatic of contamination processes occurring through internal loading from the sediments.

Residence times of 1-2 weeks in the contaminated basin (and more than 2 weeks in inner areas (Dias et al., 2001)) constitute a hindrance to mercury transport to the rest of the lagoon. Nevertheless, a hydrodynamic study of the system (Lopes et al., 2001) reported the Laranjo Basin to have high levels of suspended sediments during both flood and ebb, due to a narrow outlet channel, which is considered by the authors to have an important role in the exchange of water and cohesive sediments between the Laranjo Basin and the rest of the Lagoon. Re-suspension events are enhanced in spring tides or storms, through the erosion of mercury rich, intermediate sediment layers, which may then be bioavailable and transported to other areas of the system (Lopes et al., 2001).

Given this re-suspension events and the possible release of pore-water mercury through water currents, it is essential to evaluate and clarify the transport of this contaminant downstream from the contaminated area and its evolution following the end of the discharges to the system. According to hydrodynamic studies, it is expected that water leaving the contaminated area experience an efficient and rapid flush out toward the lagoon mouth due to low residence times (Lopes and Dias, 2007). Still, some exported mercury might in some extent reach other areas of the lagoon, increasing both the pressure in these areas and in the Atlantic marine coastal zone (Pato et al., 2008).

Studies performed in 1994 and 1999 (Pereira et al., 1998; Ramalhosa, 2002) suggest a dominance of suspended particles (suspended particulate material $(\mathrm{SPM}))$ in the mercury transport processes from the contaminated area toward the rest of the lagoon. In 1994, an estimate of $94 \mathrm{~g}$ of mercury exported associated with SPM was obtained per tidal cycle (Pereira et al., 1998). In 1999, during an equivalent spring tidal cycle, $86 \mathrm{~g}$ of mercury was transported associated with SPM, suggesting some stability in particulate mercury transport (Ramalhosa, 2002). The same study reported the dissolved fraction to have an important contribution to the overall mercury transport from the contaminated zone, with a net export of $57 \mathrm{~g}$ of dissolved reactive mercury in this fraction (Ramalhosa, 2002). In 2002, Pato and co-workers (2008) estimated a mercury flux between the lagoon and the Atlantic Ocean between 60 and $110 \mathrm{~g}$ (per tidal cycle). This consistency between mercury fluxes from the contaminated area to the rest of the lagoon and between the lagoon and the Ocean is in agreement with the low water residence time in the central area of the lagoon. Nevertheless, given the recent findings concerning bioaccumulation in estuarine biota, further knowledge is necessary on the dynamics of mercury re-suspension and transport in the system, for a thorough assessment of the system's recovery.

Some dredging of the outlet channel was conducted, as a management decision to maintain navigability, and the effects of such physical disturbances (essentially the deepening of the channel) are yet to be evaluated. Furthermore, climate change may also influence the contaminant transport processes despite all efforts to reduce anthropogenic emissions and environmental contamination, given that extreme weather events (storms and floods) may promote sediment re-suspension and enhance metal mobilization from the sediments (Kim et al., 2004). Considering the IPCC's prediction of increased occurrence of such events (IPCC, 2007), as a result of global warming and climate change, its effect on contaminant transport processes should be evaluated.

Therefore, the main aim of this research was to assess the net flux and transport processes of mercury during a spring tidal cycle at the outflow channel of the $\mathrm{Hg}$ contaminated area and compare it to previous findings (the tidal cycles performed in 1994 and 1999, (Pereira et al., 1998; Ramalhosa, 2002)) to assess the long-term evolution of the system. Moreover, an effort was made to identify possible environmental pressures prone to enhance mercury transport to the rest of the system.

\section{MATERIALS AND METHODS}

\section{Study site}

Characterized as a mesotidal system with predominantly semi-diurnal tides, the Ria de Aveiro coastal lagoon (Figure 1) has a mean tidal range of circa $2.0 \mathrm{~m}$. The 


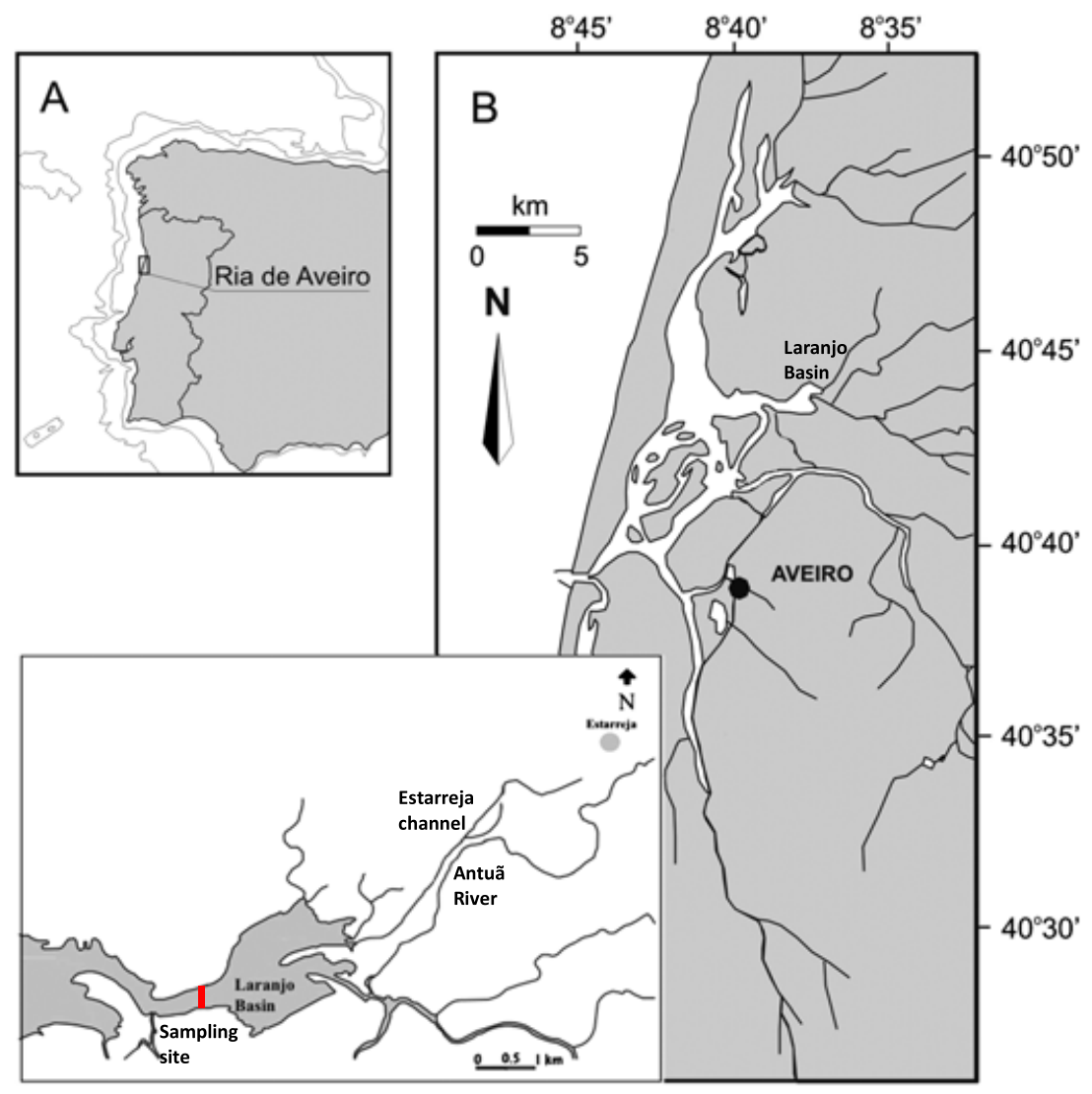

Figure 1. The Ria de Aveiro system, with indication of the studied cross section

minimum tidal range is $0.6 \mathrm{~m}$ (neap tides), and the maximum tidal range is about $3.2 \mathrm{~m}$ (spring tides), corresponding to a maximum and a minimum water level of 3.5 and $0.3 \mathrm{~m}$, respectively (Dias et al., 2000). The currents caused by the tidal wave lead to high levels of re-suspension during ebb and flood periods, mainly at spring tides (Lopes et al., 2001).

This study was performed in a narrow outlet of the Laranjo Basin, which itself constitutes a lagoon due to its semi-enclosed characteristic. It is characterized by a welldefined west-east salinity gradient between saline water, from the core of the lagoon, and freshwater from rivers and other water sources (industrial and waste waters) (Lopes et al., 2001). Sampling occurred in the narrow outlet channel from this area, with a cross-section length of about $160 \mathrm{~m}$ in low tide and about $300 \mathrm{~m}$ at high tide, while depth ranged from $1.5 \mathrm{~m}$ to a maximum of $3.7 \mathrm{~m}$ (Figure 1).

\section{Sampling}

A spring tide was chosen to evaluate higher energy conditions regarding re-suspension, given the stronger currents. Every effort was made to choose a representative tidal cycle with similar conditions to previous sampling moments (1994 and 1999), to allow direct comparisons with previous data from the long-term monitoring programme.

Triplicate subsurface water samples were collected hourly over a semi-diurnal spring tidal cycle, in April 2009, with a Van Dorn sampler. Considering the well-mixed nature of the Ria de Aveiro, as a result of the high tidal currents and shallow channels which originate both vertical and horizontal homogenization of the water column (Dias et al., 2000), homogeneity was assumed and sampling occurred in mid cross section. Water current, water column height, salinity, temperature, $\mathrm{pH}$ and dissolved oxygen were measured in situ.

\section{Laboratory methodologies}

Samples were transported to the laboratory in refrigerated boxes and immediately processed. SPM concentrations were quantified through weighting the obtained material in pre-weighted filters $(0.45 \mu \mathrm{m}$, Millipore $)$ dried after filtration of $500 \mathrm{ml}$ of water sample. Filters were digested with $\mathrm{HNO}_{3} 4 \mathrm{~mol} \mathrm{l}^{-1}$ for determination of the mercury concentration in SPM (for detailed information on the method, please refer to Pato et al., 2010).

Dissolved reactive mercury and SPM mercury analyses were performed by cold-vapour atomic fluorescence spectrometry (CV-AFS) using a PSA model Merlin 10.023 equipped with a detector PSA model 10.003, with tin chloride as reducing agent $(2 \%$ in $10 \% \mathrm{HCl})$. Total dissolved mercury concentrations were measured after chemical decomposition of sample with potassium persulfate and irradiation by a UV lamp. Following irradiation, the excess of oxidant was reduced with a hydroxylamine solution (Pato et al., 2010). Determinations were performed by CV-AFS as described for reactive mercury. 
In order to examine for any possible contamination during the filtration procedure, two blank solutions ( $100 \mathrm{ml}$ of Milli-Q water) were filtered in between the water samples through the same filtration unit used for those samples and acidified with $50 \mu \mathrm{l}$ concentrated $\mathrm{HNO}_{3}$ (Merck, 'mercury-free'). The 95\% confidence intervals (C.I) of the coefficients of variation of triplicates for the dissolved mercury samples were $15 \pm 6 \%$ and $12 \pm 6 \%$ for reactive and total fractions, respectively. For mercury analyses in the SPM, the coefficients of variation for the triplicates were $9 \pm 6 \%$ (95\% C.I.). The accuracy of mercury quantifications in the dissolved fraction was evaluated through analyses of fortified samples (recoveries of $104 \pm 3 \%$; $95 \%$ C.I.) and in the particulate fraction through analyses of certified reference materials (recoveries of $106 \pm 5$ for estuarine sediment MESS- 3 and $96 \pm 2 \%$ for harbour sediment PACS-2; 95\% C.I.).

\section{Flux estimates}

Water volume transported hourly across the section of the channel $\left(V_{i}\right)$ was determined on the basis of the current intensity and the area of the corresponding cross section over the tidal cycle. Estimates of mass exchanges (mercury and SPM) transported hourly $\left(F_{i}\right)$ across the channel were calculated by the following expression:

$$
\mathrm{F}_{\mathrm{i}}=\mathrm{V}_{\mathrm{i}} \mathrm{x}\left([\mathrm{C}]_{\mathrm{ti}}+[\mathrm{C}]_{\mathrm{ti}+1}\right) / 2
$$

Where $[\mathrm{C}]_{\mathrm{ti}}$ and $[\mathrm{C}]_{\mathrm{ti}+1}$ are the volumetric concentrations at the times $t_{i}$ and $t_{i+l}$ and $\mathrm{V}_{\mathrm{i}}$ the water volume transported between times $i$ and $i+1$.

\section{Hydrodynamic simulations}

Hydrodynamic simulations were performed to assess the influence of physical disturbance (dredging) and weather events (storms, leading to increased freshwater flows to the Laranjo Basin) on the tidal prisms of the studied channel cross section (Figure 1), in an attempt to explain the changes found on the tidal cycle results.

The hydrodynamic simulations were performed with the numerical model ELCIRC, previously calibrated and assessed to skill to the Ria de Aveiro by Picado et al. (2010).

The model was forced by tides at the ocean boundary, and the freshwater input was only considered from Vouga and Antuã rivers, the main fluvial inputs of the lagoon (Dias et al., 2000).

In this study, two different bathymetries were considered for the hydrodynamic simulations: one representing the lagoon past bathymetry and other representing the present bathymetry that includes recent dredging operations performed in the studied channel. For each bathymetry, low $\left(3 \mathrm{~m}^{3} \mathrm{~s}^{-1}\right)$ and high $\left(20 \mathrm{~m}^{3} \mathrm{~s}^{-1}\right)$ freshwater inflow from Antuã river (the main freshwater input to the Laranjo Basin) was settled as model input. For the Vouga River, the flow was set to $80 \mathrm{~m}^{3} \mathrm{~s}^{-1}$. The freshwater flow was based on the values presented by Génio et al. (2008). The tidal prism was computed through the model results for the sampling site cross section (Figure 1) for four different scenarios: past and present (including dredged operations results) local bathymetries, both forced by the same tidal input at the ocean boundary but with low and high Antuã freshwater inflows.

\section{RESULTS}

\section{Spring tidal cycle measurements}

The evolution of environmental conditions throughout the tidal cycle is summarized in Table I. Temperature $\left(13.4-16.1^{\circ} \mathrm{C}\right), \mathrm{pH}(7.2-7.9)$ and dissolved oxygen levels $\left(7.4-9.4 \mathrm{mg}^{-1}\right)$ did not show a clear pattern with tide and were fairly stable, although highest values were always observed in high water situation. Salinity, in turn, ranged from a minimum of 18.0 to a maximum of 28.7 at the end of the flood period, reflecting the intrusion of salt water into the area.

Water current and SPM concentrations are summarized in Figure 2 and are in the same range of those observed in previous tidal studies (Pereira et al., 1998; Ramalhosa, 2002). Measured water currents ranged from 0.21 to $0.40 \mathrm{~m} \mathrm{~s}^{-1}$ during flood, while during the ebb period varied between 0.11 and $0.65 \mathrm{~m} \mathrm{~s}^{-1}$, with the freshwater input from the Antuã River as the main responsible for this asymmetry. Such a difference in flood and ebb currents resulted in a downstream net water flux of circa 2 million

Table I. Dissolved oxygen $\left(\mathrm{mg} 1^{-1}\right)$, $\mathrm{pH}$, temperature $\left({ }^{\circ} \mathrm{C}\right)$ and salinity (PSU) during the spring tidal cycle

\begin{tabular}{lcccc}
\hline & $\mathbf{p H}$ & $\mathbf{O}_{\mathbf{2}}\left(\mathbf{m g} \mathbf{1}^{-\mathbf{1}}\right)$ & Temp. $\left({ }^{\circ} \mathbf{C}\right)$ & Sal. $(\mathbf{P S U})$ \\
\hline Low tide & 7.34 & 7.4 & 14.2 & 19.4 \\
LT +1 & 7.51 & 8.4 & 15.2 & 21.6 \\
LT +2 & 7.79 & 8.1 & 15.0 & 26.5 \\
LT +3 & 7.87 & 8.3 & 16.1 & 27.2 \\
LT +4 & 7.83 & 8.1 & 15.2 & 27.6 \\
LT +5 & 7.85 & 8.5 & 15.3 & 27.9 \\
High tide & 7.83 & 9.4 & 15.3 & 28.7 \\
HT +1 & 7.88 & 7.9 & 15.4 & 27.6 \\
HT +2 & 7.89 & 8.2 & 15.6 & 26.7 \\
HT +3 & 7.72 & 8.7 & 15.5 & 23.9 \\
HT +4 & 7.59 & 8.4 & 15.1 & 20.8 \\
HT +5 & 7.16 & 7.7 & 13.4 & 19.4 \\
Low tide & 7.23 & 7.4 & 13.8 & 18.0 \\
\end{tabular}

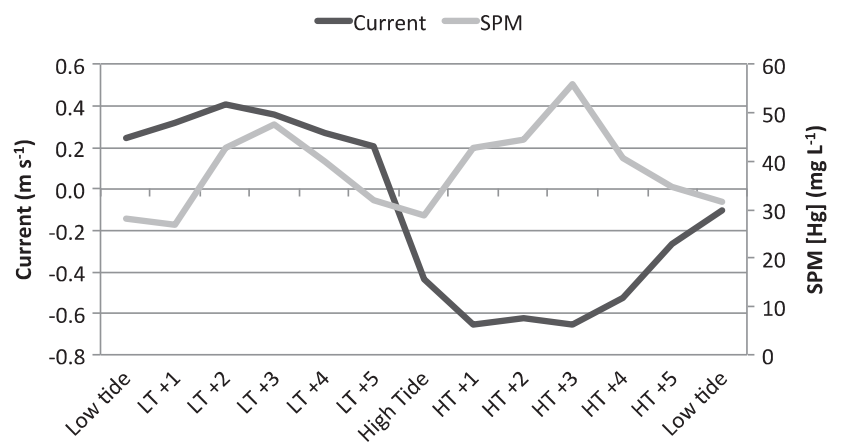

Figure 2. Water current $\left(\mathrm{m} \mathrm{s}^{-1}\right)$ and suspended particulate matter (SPM, mg $1^{-1}$ ) during the spring tidal cycle 
cubic meters across the channel cross section, during the studied tidal cycle. As a consequence of the higher currents observed, SPM concentrations were higher also in the ebb period (to a maximum of $56.1 \mathrm{mg} \mathrm{l}^{-1}$ ) than in the flood period (maximum $47.5 \mathrm{mg} \mathrm{l}^{-1}$ ), resulting in a net export of $\approx 89$ tonnes of particles during the sampling period.

Mercury concentrations in the water column followed the tidal cycle, decreasing during the flood as a result of dilution with salt water, and in agreement with the influence of the upstream contaminated area. As shown in Figure 3 , the levels of dissolved reactive mercury ranged between 4 (flood) and $14 \mathrm{ng} \mathrm{l}^{-1}$ (ebb), considerably lower than previous findings (Ramalhosa, 2002), while total dissolved mercury decreased during the flood from a maximum of $348 \mathrm{ng}^{-1}$ observed at low tide to a minimum of $96 \mathrm{ng}^{-1}$ at high tide. Both dissolved mercury forms were quantified to permit comparisons with previous cycles, which did not determine total dissolved mercury. This may have underestimated the dissolved mercury transport, given that reactive mercury in the 2009 cycle represented only between $3 \%$ and $12 \%$ of total dissolved mercury. A distinct pattern was observed along the cycle: during the flood, the reactive fraction remained stable at around $4 \%$, increasing during the ebb to $8-12 \%$.

Concerning the particulate fraction of the water column, the overall pattern found was similar to the one observed in the dissolved fraction (Figure 4). Lower mercury contents were found at high tide $\left(0.32 \mathrm{mg} \mathrm{kg}^{-1}\right)$,

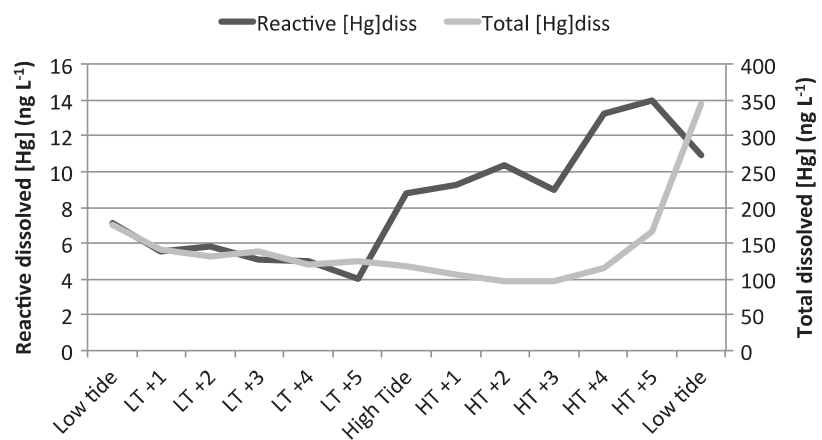

Figure 3. Total and reactive dissolved mercury concentrations $\left(\right.$ ng $\left.1^{-1}\right)$ during the spring tidal cycle

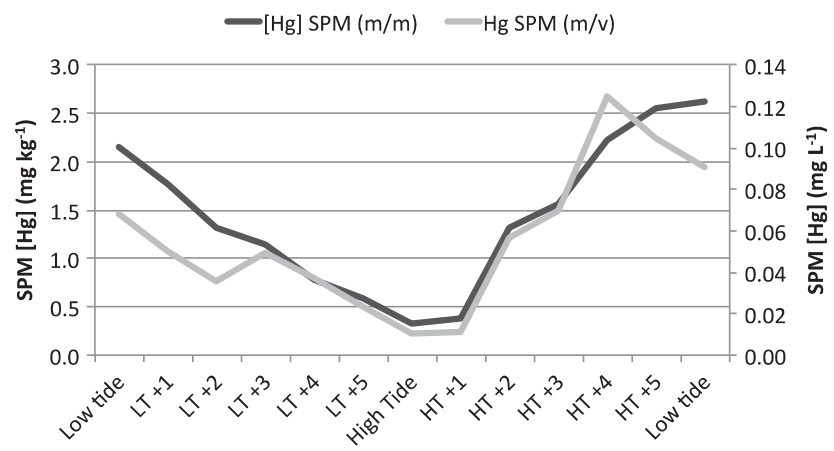

Figure 4. Suspended particulate matter-associated mercury $\left(\mathrm{mg} \mathrm{kg}^{-1}\right.$; $\mathrm{mg}^{-1}$ ) during the spring tidal cycle and a mercury enrichment of particles was observed during the ebb, to a maximum of $2.6 \mathrm{mg} \mathrm{kg}^{-1}$. Mercury levels are within the range reported by Pereira and co-workers in the 1994 cycle (Pereira et al., 1998), but considerably lower (nearly $1 / 3$ ) than those observed in 1999 by Ramalhosa (2002) (Figure 5).

With all the considerable differences between the ebb and flood period, in terms of water flux, suspended particles and contaminant concentrations, a scenario of mercury export from the contaminated area to the rest of the system emerges (Figure 6). The net flux of mercury associated with the dissolved fraction was $184 \mathrm{~g}$, of which $31 \mathrm{~g}$ corresponded to reactive dissolved mercury. This contrasts with previous findings, given that the tidal cycles in 1994 and 1999 reported nearly four times less dissolved mercury exported than in 2009. Regarding particulate export, $201 \mathrm{~g}$ was associated with this fraction per tidal cycle, more than double the amount transported in previous cycles (Figure 7).
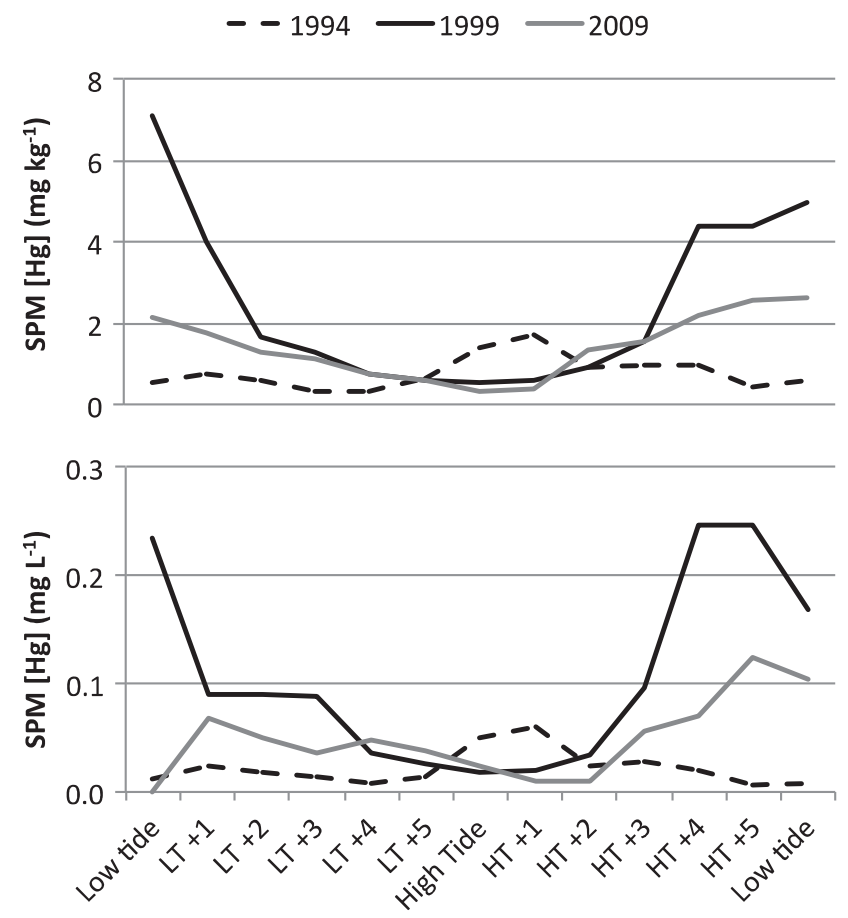

Figure 5. Suspended particulate matter-associated mercury $\left(\mathrm{mg} \mathrm{kg}^{-1}\right.$; $\mathrm{mg} \mathrm{l}^{-1}$ ) in the tidal cycles of 1994, 1999 and 2009

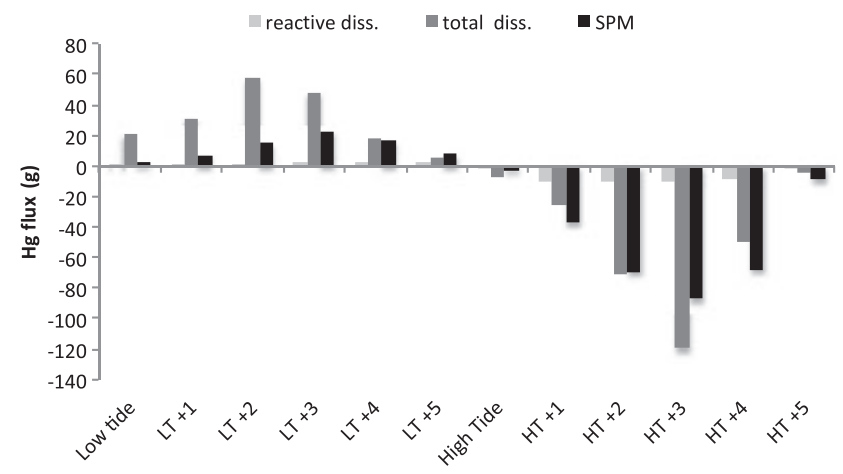

Figure 6. Mercury fluxes (g) associated with the reactive dissolved, total dissolved and particulate (SPM) fractions during the spring tidal cycle 


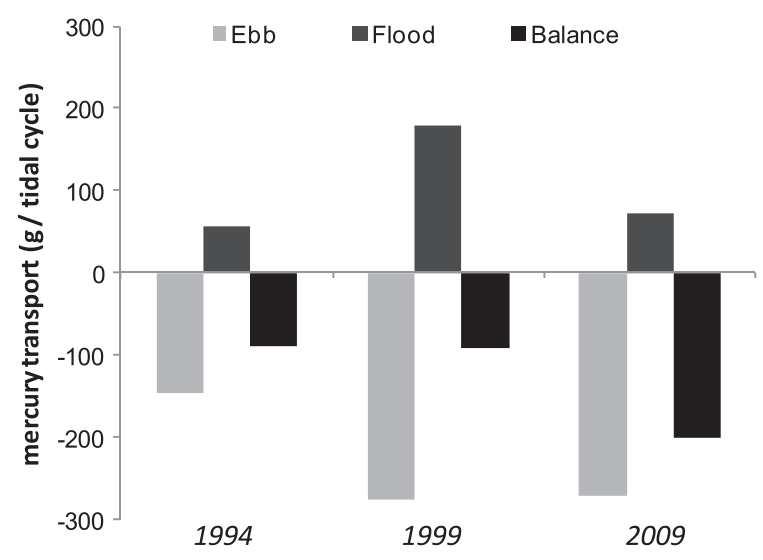

Figure 7. SPM-associated mercury (g) transported during the tidal cycles of 1994,1999 and 2009

\section{Hydrodynamic simulations}

Bearing in mind the increase in the net export of mercury from the Laranjo Basin observed in 2009, and considering the water mass balance increase as the main forcing function for these results, hydrodynamic simulations were conducted to investigate its origin. The aim was to evaluate the possible effects that recent dredging events and high precipitation (leading to the increase of freshwater inflow from the Antuã River) could have in the tidal prisms at the sampling site, and thus explaining the obtained field results.

The results of the numerical simulations are presented in Figure 8 for spring tide condition, for two different bathymetries (past and dredged) and for low and high river inflow. The changes in tidal prism found between past and dredged scenarios are not significant. However, low freshwater inflow results in a slight flood net water volume transport along a tidal cycle, while with high freshwater inflow (corresponding to extreme precipitation events and flooding) a significant ebb net water volume transport was found. Results suggest therefore that weather events resulting in increased freshwater input may be considered the main forcing function determining

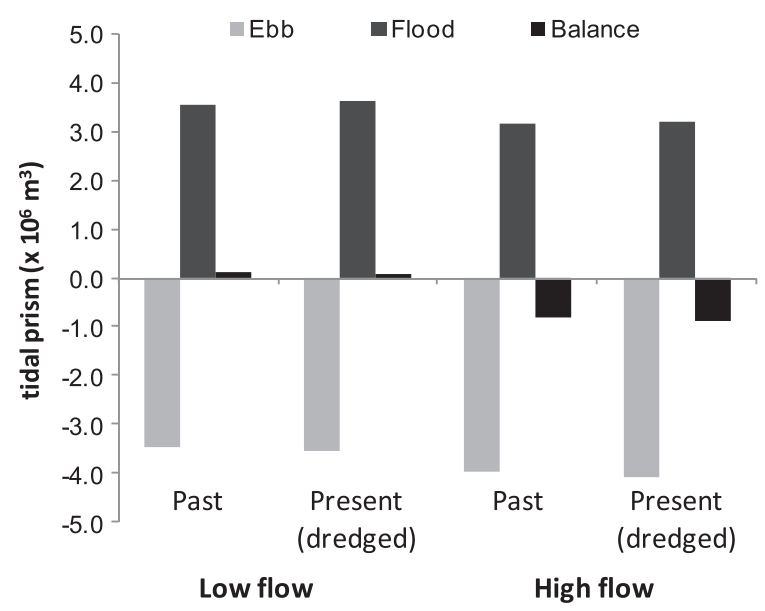

Figure 8. Hydrodynamic simulations of the tidal prism in the sampling site, with changes in channel depth (dredging) and increased freshwater flow (high flow) the tidal prism changes on Laranjo Basin and consequently the changes reported on the mercury transport in this survey.

\section{DISCUSSION}

The recovery of historically contaminated areas is a complex process involving numerous variables, which will influence the de-contamination strategy to adopt, whether capping, dredging or natural attenuation (Wang et al., 2004). An evaluation of mercury transport and transformation in the environment is a critical component of such strategies, as a result of the many processes involved, such as hydrodynamic and sediment processes, mercury transport and chemical reactions and transformations (Wang et al., 2004).

Results from this study highlight the usefulness of a long-term monitoring approach to assess environmental condition evolution. While previous work on mercury transport processes in the area suggested a relatively stable situation, with two studies 5 years apart reporting similar mercury tidal fluxes associated with SPM (Pereira et al., 1998; Ramalhosa, 2002), little information exists with regards to the dissolved fraction mercury transport. While most authors highlight the importance of particulate mercury transport (Kim et al., 2004; Paraquetti et al., 2004; Hissler and Probst, 2006), others report the opposite (Bushey et al., 2008), therefore justifying a more in-depth evaluation of mercury partition and transport processes.

\section{Mercury associated with the dissolved fraction}

The present results show that the dissolved fraction has a contribution to the mercury transport comparable to the role played by suspended particles. Fluxes calculated based on reactive dissolved mercury revealed a decrease in the dissolved mercury transport through the studied cross section with time $(0.03 \mathrm{~kg}$ as opposed to $0.057 \mathrm{~kg}$, (Ramalhosa, 2002)), as a result of the lower reactive mercury concentrations observed during the cycle. However, fluxes of total dissolved mercury were similar to what was observed for the particulate fraction and suggest the importance of dissolved mercury transport to have been underestimated in previous tidal cycles, given that only dissolved reactive and not total dissolved mercury was quantified. In fact, during the tidal cycle mercury was found evenly associated between the dissolved and particulate fraction (to a maximum of $52 \%$ ), with the logarithm of the distribution coefficient $\left(\mathrm{K}_{\mathrm{d}}\right)$ ranging between 3.4 and 4.3. The observed $\mathrm{K}_{\mathrm{d}}$ values indicate a lower contribution of the particulate fraction than expected by the results of partitioning frequently reported for other estuaries ( $\log \mathrm{K}_{\mathrm{d}}$ of 5-6) (Coquery et al., 1997; Laurier et al., 2003) and observed in the lagoon-ocean interface (Pato et al., 2010). These results evidence that in estuaries, the dissolved fraction can play a significant role as carrier of mercury, and therefore the evaluation of the role of this fraction in transport processes should be considered. The partitioning 
of mercury between the dissolved fraction and SPM is highly variable and influenced by several factors (complexation with organic matter present in both fractions and in different content and nature, association with particulate amorphous phases, complexation with inorganic ligands, ionic strength) governing complex biogeochemical equilibriums within the water column (Coquery et al., 1997; Conaway et al., 2003; Laurier et al., 2003).

The high range of total dissolved mercury concentrations can be a result of mobilization of mercury associated with particles and leaching of enriched pore waters by stronger currents. Results from several studies suggest that mercury is strongly bound (and quasi-irreversibly) to particles when associated to high-energy binding sites, and therefore minor fractions are released during re-suspension and estuarine transit (Le Roux et al., 2001; Kim et al., 2004; Covelli et al., 2009). However, the contaminated particles from sulphur rich sediments, once remobilized into the water column, encounter an aerobic environment and start re-establishing a new quasi-equilibrium, desorbing particulate mercury to the dissolved fraction, resulting in the decrease of particulate mercury and subsequent increase of dissolved mercury (Hissler and Probst, 2006).

The increase of reactive mercury due to the formation of chloro-complexes would be expected during the flood as salinity increases, but was not observed, reinforcing the importance of organic matter to the speciation and partition of mercury (Laurier et al., 2003). In fact, the competition between dissolved organic matter and binding sites in particles is responsible for the distribution between the suspended particles and the dissolved fraction, which plays a critical role in the transport and fate of mercury in the aquatic environments.

The low reactive fraction of dissolved mercury can alternatively be related with the presence of non-labile colloidal mercury in the dissolved fraction, as colloidal $\mathrm{Hg}$ can represent a major fraction of the filter-passing pool (Guentzel et al., 1996). Therefore, re-suspension of colloidal particles contributes to higher total dissolved mercury levels (than the truly dissolved levels), leading to lower distribution coefficients than usually reported in estuarine systems (Coquery et al., 1997). As dissolved mercury (both truly dissolved and slow settling particles) can be transported through longer distances, higher dispersion and possible impact of mercury should be expected over a broader area.

\section{Mercury associated with the particulate fraction}

SPM concentrations increased in high flow periods, as a result of remobilization of coarser sediments through increased water currents, reflected in the positive correlation found between water current and SPM concentrations (Pearson's correlation coefficient, $r=0.673, p=0.12$ ). Moreover, observed SPM concentrations were considerably high, at times exceeding $50 \mathrm{mg}^{-1}$, in agreement with previous findings which reported this area to have high levels of suspended sediments during both flood and ebb (Lopes et al., 2001). Taking into consideration the high turbidity characteristics of the area, transport processes and mercury export may therefore be enhanced.

Mercury concentrations during the tidal cycle reflected the upstream contamination source, with the highest concentrations recorded during the ebb period. These results suggest remobilization of particulate material from upstream, contaminated bed sediments with tidal currents and seawards transport through the studied cross section. High SPM concentrations were also found in flood periods, but the corresponding mercury content was considerably lower, from what is possible to infer some degree of unidirectionality in the transport processes across the studied section. Furthermore, the dilution of mercury levels by cleaner particles transported upstream with tidal currents is a possibility, as suggested by several authors (Lopes et al., 2001; Covelli et al., 2007).

Given the strong tendency for mercury to bind with particulate matter (Lawson et al., 2001), this fraction tends to play a predominant role in the transport processes occurring in aquatic systems (Kim et al., 2004; Paraquetti et al., 2004). In similar studies, Covelli and co-workers (2009) and Hissler and Probst (2006) observed the mercury transport from decommissioned chlor-alkali plants to be mainly associated with the suspended particulate phase and controlled by dissolved ligands and total suspended solids. Both studies reported a decrease of particle-associated mercury with increasing salinity, probably as a result of the weaker bonding of mercury to $\mathrm{Cl}^{-}$-complexes than to $\mathrm{OH}^{-}$-complexes, prevalent in freshwaters (Morel et al., 1998). Salinity in our study ranged from 18 to 29 , considerably higher than the reported by both Covelli and co-workers (2009) and Hissler and Probst (2006), and possibly the reason for the less dominant binding of mercury to particulate matter.

Considering that no mercury discharges have occurred for more than 15 years, a natural remediation process is underway in the area, through burial of contaminated sediment layers by settling of cleaner sediments. The progressive reduction of surface sediment mercury contamination should minimize metal re-mobilization, and therefore lower SPM mercury concentrations and transport through time. A sustained comparison of the long-term temporal evolution of total mercury transport associated with SPM was considered feasible, given that these measurements were performed in three tidal cycles through the last 15 years.

Overall, SPM mercury concentrations during the 2009 tidal cycle were comparable with levels from 1994 (Pereira et al., 1998) and lower than those observed in 1999 (up to $7 \mathrm{mg} \mathrm{kg}^{-1}$, nearly three times higher than present results (Ramalhosa, 2002), Figure 5). Sedimentary mercury concentrations and profiles have been periodically monitored in the system. Pereira and co-workers (1997) observed a range of superficial concentrations from $63 \mathrm{mg} \mathrm{kg}^{-1}$ at the end of the Estarreja channel to $7.9 \mathrm{mg} \mathrm{kg}^{-1}$ in the outlet of the Laranjo Basin, and the analysis of a 
sediment core reported maximum $\mathrm{Hg}$ concentrations at $12-13 \mathrm{~cm}$ depth. A more recent study (Ramalhosa et al., 2001) reported the maximum $\mathrm{Hg}$ levels in sediments at depths between 20 and $30 \mathrm{~cm}$, and surface concentrations in the range of $4-20 \mathrm{mg} \mathrm{kg}^{-1}$. Recent data (from 2011, unpublished results) provide further support of the recovery of the system, with superficial concentrations in the range of 2-8 $\mathrm{m} \mathrm{kg} \mathrm{k}^{-1}$, and maximum concentrations at $25-40 \mathrm{~cm}$ depth. However, and contrary to what could be expected from the evolution of surface sedimentary mercury levels and burial of the most contaminated sediment layers, net export of mercury associated with SPM in 2009 doubled the results obtained in previous tidal cycles, infirming the hypothesis of an expected decay of particulate mercury export from the Laranjo Basin.

Considering that the mercury contents of SPM in the tidal cycles do not justify the observed differences, these results are mainly a consequence of variations in tidal prisms. The water exchanges calculated by field measurements of current velocities and channel cross section revealed a decrease of flood tidal prism over the tidal cycles (1994, 1999 and 2009). In addition, the latter tidal cycle showed the highest ebb tidal prism, resulting in a net tidal prism three times larger than in previous studies.

Several studies have highlighted the importance of re-suspension and hydrodynamics on contaminant transport (Paraquetti et al., 2004; Covelli et al., 2007), and point out both natural events (wind waves and especially storm events) and anthropogenic activities (mainly dredging and trawling) as the key forcing functions responsible for enhanced re-suspension and transport (Kim et al., 2004). While dredging activities (for ship access) will deepen channels and may alter the flow regime by enhancing water circulation and current velocities, through a reduction in bed friction (Araújo et al., 2008), floods and storm events will increase water flow and promote re-suspension, being considered the major vector for particle and contaminant transport in aquatic systems (Mason and Sullivan, 1998; Paraquetti et al., 2004; Bushey et al., 2008). Accordingly, both forcing functions were tested through modelling, to evaluate the core vector regulating the tidal prism and associated mercury transport in the system.

\section{Hydrodynamic simulations on the studied area}

In an effort to explain the changes in the tidal prism during the studied tidal cycle, responsible for the increased mercury transport observed, hydrodynamic simulations were conducted to test the response of the system to both bottom dredging (which had recently been performed to maintain channel navigability) and increased freshwater inflow from the Antuã River (as a result of recent high precipitation events).

According to the model results, the channel dredging alone has little influence on the tidal prism values. In fact, for flood and ebb, the tidal prism slightly increases at rates of $1.5 \%$ and $2.5 \%$, respectively. Otherwise, the increase in freshwater input alone would decrease the tidal prism in about $11 \%$ during flood and increase about $14 \%$ during ebb, respectively. When both situations were considered (dredging plus high flow) an increase of approximately $18 \%$ on ebb tidal prism and a decrease of $10 \%$ on flood tidal prism were found, in agreement with the observations reported, resulting in an increased net water efflux from the Laranjo Basin. Changes in tidal prisms will additionally favor mercury transport downstream, and hinder mercury re-entrance in the Basin with flood currents.

Despite the synergistic effect of both dredging and the increase of freshwater input from the Antuã river better reflect the experimental results obtained, the latter may be considered the main forcing function influencing the tidal prism at the Laranjo Basin outlet, and consequently determining the mercury transport changes observed for the area under study.

In a time of scientific awareness towards the effects of climate change in ecosystems, this study, while not categorically demonstrating that increased storm flows have enhanced $\mathrm{Hg}$ mobility and export, contributes by highlighting the importance of monitoring historically contaminated sites, which can become increasingly problematic as a result of climatic changes. With highenergy phenomena such as storms and floods becoming more common, the re-suspension of bed sediments and the increased water flow passing through contaminated areas may enhance contaminant re-mobilization and transport.

These findings therefore emphasize the need for further research regarding the effects of climate change and the increase of high-energy phenomena and storm flows as a major forcing function for particle and contaminant transport in aquatic systems.

\section{CONCLUSIONS}

These results stress the importance of long-term monitoring programs, since despite an overall improvement in local contamination levels, visible in both the sedimentary compartment and the water column, the enhancement of transport processes increases environmental pressure away from the contamination source, thus justifying further research. Also, and given the possible direct coupling between the freshwater inflow and effective mercury transport, additional attention should be given to the effect of climatic change and high energy phenomena (in this case, essentially storms) on the mercury mobilization and transport processes, as such events may result in episodic toxicity events in other areas of the system or adjacent coastal areas.

\section{ACKNOWLEDGEMENTS}

This work was financed by the Portuguese Foundation for Science and Technology (FCT) through a Post-Doc grant to J.P. Coelho (SFRH/BPD/48449/2008) and P. Pato (SFRH/BPD/35068/2007). 


\section{REFERENCES}

Araújo IB, Dias JM, Pugh DT. 2008. Model simulations of tidal changes in a coastal lagoon, the Ria de Aveiro (Portugal). Continental Shelf Research 28: 1010-1025.

Berzas Nevado JJ, García Bermejo LF, Rodríguez Martín-Doimeadios, RC. 2003. Distribution of mercury in the aquatic environment at Almadén, Spain. Environmental Pollution 122: 261-271.

Burt TP, Howden NJK, Worrall F, Whelan MJ. 2008. Importance of longterm monitoring for detecting environmental change: lessons from a lowland river in south east England. Biogeosciences 5: 1529-1535.

Bushey JT, Driscoll CT, Mitchell MJ, Selvendiran P, Montesdeoca MR. 2008. Mercury transport in response to storm events from a northern forest landscape. Hydrological Processes 22: 4813-4826.

Coelho JP, Rosa M, Pereira E, Duarte A, Pardal MA. 2006. Pattern and annual rates of Scrobicularia plana mercury bioaccumulation in a human induced mercury gradient (Ria de Aveiro, Portugal). Estuar Coast Shelf S 69: 629-635.

Coelho JP, Reis AT, Ventura S, Pereira ME, Duarte AC, Pardal MA. 2008. Pattern and pathways for mercury lifespan bioaccumulation in Carcinus maenas. Marine Pollution Bulletin 56: 1104-1110.

Conaway CH, Squire S, Mason RP, Flegal AR. 2003. Mercury speciation in the San Francisco Bay estuary. Marine Chemistry 80: 199-225.

Conaway CH, Watson EB, Flanders JR, Flegal AR. 2004. Mercury deposition in a tidal marsh of south San Francisco Bay downstream of the historic New Almaden mining district, California. Marine Chemistry 90: $175-184$.

Coquery M, Cossa D, Sanjuan J. 1997. Speciation and sorption of mercury in two macro-tidal estuaries. Marine Chemistry 58: 213-227.

Covelli S, Piani R, Acquavita A, Predonzani S, Faganeli J. 2007. Transport and dispersion of particulate $\mathrm{Hg}$ associated with a river plume in coastal Northern Adriatic environments. Marine Pollution Bulletin 55: 436-450.

Covelli S, Acquavita A, Piani R, Predonzani S, De Vittor C. 2009. Recent contamination of mercury in an estuarine environment (Marano lagoon, Northern Adriatic, Italy). Estuarine, Coastal and Shelf Science 82: 273-284.

Dias JM, Lopes JF, Dekeyser I. 2000. Tidal propagation in Ria de Aveiro Lagoon, Portugal. Physics and Chemistry of the Earth, Part B: Hydrology, Oceans and Atmosphere 25: 369-374.

Dias JM, Lopes JF, Dekeyser I. 2001. Lagrangian transport of particles in Ria de Aveiro lagoon, Portugal. Physics and Chemistry of the Earth, Part B: Hydrology, Oceans and Atmosphere 26: 721-727.

Gagnon C, Pelletier E, Mucci A. 1997. Behaviour of anthropogenic mercury in coastal marine sediments. Marine Chemistry 59: 159-176.

Génio L, Sousa A, Vaz N, Dias JM, Barroso C. 2008. Effect of low salinity on the survival of recently hatched veliger of Nassarius reticulatus (L.) in estuarine habitats: A case study of Ria de Aveiro. Journal of Sea Research 59: 133-143.

Guentzel JL, Powell RT, Landing WM, Mason RP: 1996. Mercury associated with colloidal material in an estuarine and an open-ocean environment. Marine Chemistry 55, 177.

Harland BJ, Taylor D, Wither K. 2000. The distribution of mercury and other trace metals in the sediments of the Mersey Estuary over 25 years 1974-1998. Science Of The Total Environment 253: 45-62.

Hissler C, Probst J-L. 2006. Chlor-alkali industrial contamination and riverine transport of mercury: Distribution and partitioning of mercury between water, suspended matter, and bottom sediment of the Thur River, France. Applied Geochemistry 21: 1837-1854.

Horvat M, Covelli S, Faganeli J, Logar M, Mandić V, Rajar R, Širca A, Žagar D. 1999. Mercury in contaminated coastal environments; a case study: the Gulf of Trieste. Science of the Total Environment 237-238, 43-56.

Ip CCM, Li XD, Zhang G, Farmer JG, Wai OWH, Li YS. 2004. Over one hundred years of trace metal fluxes in the sediments of the Pearl River Estuary, South China. Environmental Pollution 132, 157-172.

IPCC. 2007. Climate Change 2007: Synthesis Report - Contribution of Working Groups I, II and III to the Fourth Assessment Report of the Intergovernmental Panel on Climate Change in: Pachauri RK, Reisinger A. (Eds.). IPCC: Geneva; 104.

Kennish MJ. 1996. Practical Handbook of Estuarine and Marine Pollution. CRC Press: Boca Raton.

Kim EH, Mason RP, Porter ET, Soulen HL. 2004. The effect of resuspension on the fate of total mercury and methyl mercury in a shallow estuarine ecosystem: a mesocosm study. Marine Chemistry 86: $121-137$.

Laurier FJG, Cossa D, Gonzalez JL, Breviere E, Sarazin G. 2003. Mercury transformations and exchanges in a high turbidity estuary: The role of organic matter and amorphous oxyhydroxides. Geochimica et Cosmochimica Acta 67: 3329-3345.

Laurier FJG, Mason RP, Gill GA, Whalin L. 2004. Mercury distributions in the North Pacific Ocean - 20 years of observations. Marine Chemistry 90: 3-19.

Lawson NM, Mason RP, Laporte JM. 2001. The fate and transport of mercury, methylmercury, and other trace metals in Chesapeake Bay tributaries. Water Research 35: 501-515.

Le Roux SM, Turner A, Millward GE, Ebdon L, Appriou P. 2001. Partitioning of mercury onto suspended sediments in estuaries. $J$ Environ Monitor 3: 37-42.

Lopes JF, Dias JM, Dekeyser I. 2001. Influence of tides and river inputs on suspended sediment transport in the Ria de Aveiro lagoon, Portugal. Physics and Chemistry of the Earth, Part B: Hydrology, Oceans and Atmosphere 26: 729-734.

Lopes JF, Dias JM. 2007. Residual circulation and sediment distribution in the Ria de Aveiro lagoon, Portugal. Journal of Marine Systems 68 : 507-528.

Mason RP, Sullivan KA. 1998. Mercury and methylmercury transport through an urban watershed. Water Research 32: 321-330.

Mason RP, Kim EH, Cornwell J. 2004. Metal accumulation in Baltimore Harbor: current and past inputs. Applied Geochemistry 19: 1801-1825.

Mclusky DS, Elliot M. 2004. The Estuarine Ecosystem (ecology, threats and management). Oxford University Press: Oxford.

Morel FMM, Kraepiel AML, Amyot M. 1998. The chemical cycle and bioaccumulation of mercury. Annual Review of Ecology and Systematics 29: 543-566.

OSPAR. 2004. Mercury losses from the chlor-alkali industry (1982-2002). Hazardous Substances series. OSPAR Comission, 39.

Paraquetti HHM, Ayres GA, de Almeida MD, Molisani MM, Lacerda LDD. 2004. Mercury distribution, speciation and flux in the Sepetiba Bay tributaries, SE Brazil. Water Research 38: 1439-1448.

Pato P, Lopes C, Válega M, Lillebø AI, Dias JM, Pereira E, Duarte AC. 2008. Mercury fluxes between an impacted coastal lagoon and the Atlantic Ocean. Estuar Coast Shelf S 76: 787-796.

Pato P, Otero M, Vlega M, Lopes CB, Pereira ME, Duarte AC. 2010. Mercury partition in the interface between a contaminated lagoon and the ocean: The role of particulate load and composition. Marine Pollution Bulletin 60: 1658-1666.

Pereira ME, Duarte AC, Millward GE, Abreu SN, Reis MC. 1997. Distribution of mercury and other heavy metals in the Ria de Aveiro. Quimica Analitica 16: 31-35.

Pereira ME, Duarte AC, Millward GE, Vale C, Abreu SN. 1998. Tidal export of particulate mercury from the most contaminated area of Aveiro's Lagoon, Portugal. Science of the Total Environment 213: 157-163.

Pereira ME, Lillebo AI, Pato P, Valega M, Coelho JP, Lopes CB, Rodrigues S, Cachada A, Otero M, Pardal MA, Duarte AC. 2009. Mercury pollution in Ria de Aveiro (Portugal): a review of the system assessment. Environmental Monitoring and Assessment 155: 39-49.

Picado A, Dias JM, Fortunato AB. 2010. Tidal changes in estuarine systems induced by local geomorphologic modifications. Continental Shelf Research 30: 1854-1864.

Ram A, Rokade MA, Borole DV, Zingde MD. 2003. Mercury in sediments of Ulhas estuary. Marine Pollution Bulletin 46: 846-857.

Ramalhosa E, Monterroso P, Abreu S, Pereira E, Vale C, Duarte A. 2001. Storage and export of mercury from a contaminated bay (Ria de Aveiro, Portugal). Wetlands Ecology and Management 9: 311.

Ramalhosa E. 2002. Mercúrio na Ria de Aveiro: associações, reactividade e especiação. Chemistry Department. University of Aveiro, Aveiro, 353.

Ridal JJ, Yanch LE, Fowlie AR, Razavi NR, Delongchamp TM, Choy ES, Fathi M, Hodson PV, Campbell LM, Blais JM, Hickey MBC, Yumvihoze E, Lean DRS. 2010. Potential causes of enhanced transfer of mercury to St. Lawrence River Biota: implications for sediment management strategies at Cornwall, Ontario, Canada. Hydrobiologia 647: 81-98.

Wang Q, Kim D, Dionysiou DD, Sorial GA, Timberlake D. 2004. Sources and remediation for mercury contamination in aquatic systems - a literature review. Environmental Pollution 131: 323-336. 